\title{
Preliminary Design and Analysis of the ARES Atmospheric Flight Vehicle Thermal Control System
}

\author{
J.F. Gasbarre, R.A. Dillman \\ NASA Langley Research Center, Hampton, VA 23681
}

\section{ABSTRACT}

The Aerial Regional-scale Environmental Survey (ARES) is a proposed 2007 Mars Scout Mission that will be the first mission to deploy an atmospheric flight vehicle (AFV) on another planet. This paper will describe the preliminary design and analysis of the AFV thermal control system for its flight through the Martian atmosphere and also present other analyses broadening the scope of that design to include other phases of the ARES mission. Initial analyses are discussed and results of trade studies are presented which detail the design process for AFV thermal control. Finally, results of the most recent AFV thermal analysis are shown and the plans for future work are discussed.

\section{MISSION DESCRIPTION}

ARES is one of four competing proposals for the 2007 Mars Scout Mission. It will be the first mission to fly an aircraft on another planet, and will return high-resolution regional-scale data on Mars' atmospheric chemistry, surface chemistry, and remnant crustal magnetism (Ref. 1). ARES will launch from Earth on a Delta II rocket (Ref. 2), with the airplane folded inside an entry aeroshell attached to a carrier spacecraft. After a 12month cruise to Mars, the carrier spacecraft will release the aeroshell on a Mars-intercept trajectory and diverts its own path to begin service as a communications link. The aeroshell then coasts toward Mars for nine hours, spin-stabilized to maintain the proper attitude at atmospheric interface. After protecting the payload from entry heating and deceleration, the aeroshell releases the rocket-propelled airplane, which deploys its wings and tail and pulls up from the entry dive into level flight. Engineering and science data are collected on board the airplane and transmitted to the carrier spacecraft for relay back to Earth.

\section{VEHICLE CONFIGURATION}

The airplane's fuselage length and wingspan were driven by the need to fit inside the entry aeroshell, which was sized to fit the Delta II launch shroud, and by a project decision to limit the number of deployments in order to increase reliability. The airplane has one fold in each wing and another where the twin tail booms attach to the end of the fuselage. The Delta II payload capability did not initially pose a limitation; the mass of the airplane was driven by how much it could carry and still pull out of the entry dive and into level flight. Figure 1 shows the airplane in both the stowed-for-launch and the deployed configuration.

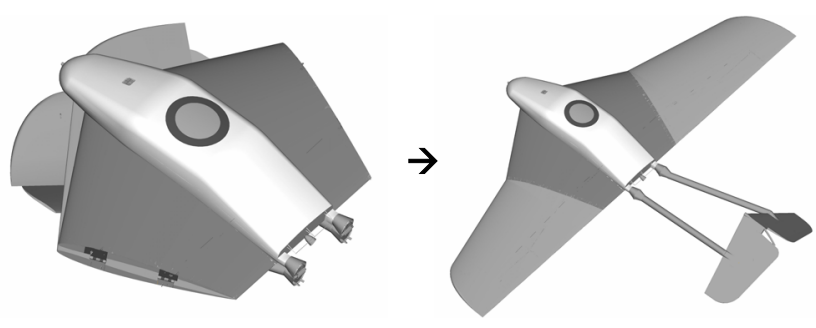

Figure 1 - Airplane Configuration, Stowed $\rightarrow$ Deployed

The airplane wings are full depth aluminum honeycomb with composite face sheets, reinforced with spars connecting the pairs of wing hinges to and through the fuselage. For the analyses described in this paper, the wing structure continues through the center of the plane, joining the wings and forming the lower surface of the fuselage; most of the airplane hardware mounts to the honeycomb surface. The upper skin of the fuselage is a honeycomb sandwich, sized to support its own weight and the few components attached to it.

\section{COMPONENT LAYOUT}

The science instruments generally had specific requirements to drive their location. The mass spectrometer needed to be at the vehicle nose, so that it 
would be upwind of any fumes, exhaust, or water vapor emitted by the airplane; the associated electronics needed to be nearby. The magnetometers needed to be in the wingtips, to give horizontal separation and keep them as far as possible from the magnetic fields of the fuselage-mounted avionics and actuators. The point spectrometer and context camera, however, needed only to be nadir viewing, and could be placed almost anywhere in the belly of the airplane; the point spectrometer electronics needed to be near their instrument.

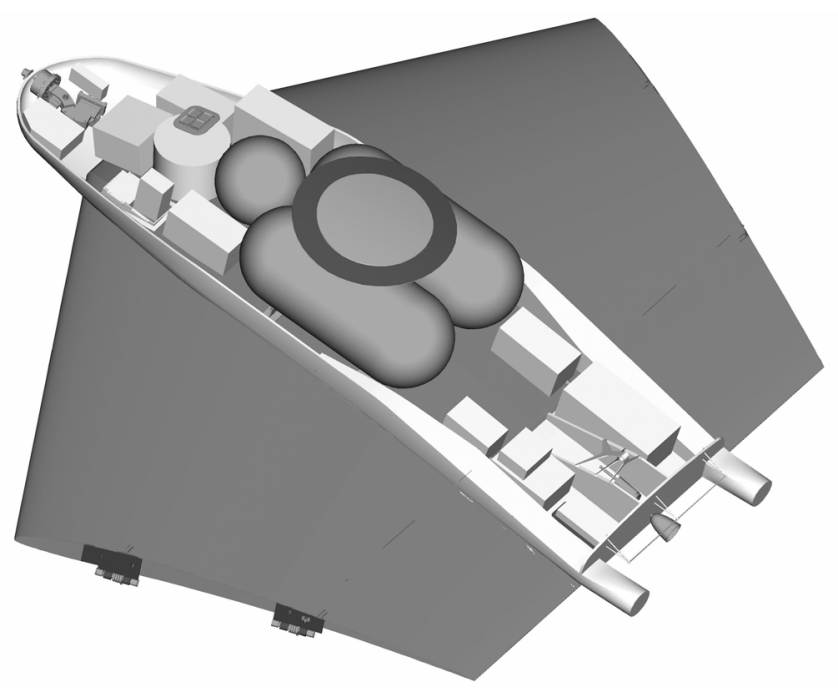

Figure 2 - Component Layout in ProEngineer

Most major airplane components also had sufficient requirements to define their location. The propellant tanks needed to be placed at or near the vehicle center of gravity (CG) to minimize changes in CG location, and consequently in vehicle stability, as the on-board propellant mass decreased during flight. These cylindrical tanks were relatively large and, along with the spherical helium tank used to pressurize the propulsion system, effectively divided the fuselage into two separate (forward and aft) equipment bays. The rocket nozzle was placed at the aft end of the fuselage to keep the hot exhaust clear of the rest of the vehicle, and on the vehicle centerline to avoid inducing yaw moments. Batteries and the main power switchbox were placed in the aft bay, on the starboard side of the rocket nozzle, to keep the electrical noise of the power switches far from the science electronics. The UHF patch antenna was placed atop the fuselage, for the best view of the spacecraft overhead during level flight. The linear wire antenna was placed across the aft end of the fuselage, to provide an aft field of view for transmitting vehicle status information to the spacecraft while the airplane is still in its deployment dive. The transmitter assembly (transceiver, diplexer, and power amplifier) was placed on the port side of the aft bay, close to the linear antenna and with easy access to the patch antenna. The flight computer and inertial measurement unit were placed with the instrument electronics in the forward bay. The center of the aft bay was left open for future use by propellant lines, valves, filters, etc; a significant portion of the forward bay remained open as well, for later equipment additions and repackaging. The ProEngineer (Ref 3) CAD model of the overall component layout is shown in Figure 2.

\section{CHARACTERIZATION OF THE FLIGHT THERMAL ENVIRONMENT}

Due to the unique nature of flying an airplane on another planet, the largest amount of risk for most subsystems was believed to be during the flight phase of the mission. Therefore, the design of a thermal control system that met the needs of the aircraft in flight was of paramount importance. A UHF communications system was deemed the most viable option for communications between the AFV and the carrier spacecraft. Unfortunately from a thermal perspective, the UHF system included an amplifier that was to dissipate 100 W. It was assumed that this area of the AFV fuselage would be a spot of extreme localized heating, but there was no a priori knowledge of what other areas might create additional thermal concerns. An initial FEM model was developed of the entire fuselage and the wing sections inboard of the hinge line to assist in revealing any thermal issues during flight and to aid in the development of thermal control solutions for any problem areas. A listing of the minimum and maximum operating temperatures and the flight heat dissipation values of each component is presented in Table 1, Appendix 1.

\section{LITERATURE REVIEW}

Due to the unfamiliar nature of the Martian atmospheric environment, an extensive literature review was undertaken. The majority of time was spent investigating what the convection and radiation heat transfer environments would be like in this foreign atmosphere. The Martian atmosphere is over 95\% carbon dioxide (Ref. 4), which allowed the assumption that all convection occurs in pure $\mathrm{CO}_{2}$. To obtain the parameters needed to compute both the external forced convection on the vehicle and the internal natural convection (for internal component cooling), references 5 and 6 were consulted for $\mathrm{CO}_{2}$ at low temperatures and pressures. The temperature, pressure, and density of the $\mathrm{CO}_{2}$ were outputs of the MarsGRAM 2001 program (Ref. 7) that was used to predict the atmospheric properties for the range of possible flight days. While the forced convection equations were developed using 
flat-plate theory for both a laminar and turbulent boundary layer (Ref. 8), the natural convection equations found in most textbooks required further development. Most are based on empirical relations for natural convection in air, but applying them to a $\mathrm{CO}_{2}$ environment would be incorrect. Therefore, the natural convection equations listed below are based on the original similarity solution (Refs. 9, 10) developed for natural convection for a constant-wall heat flux, since the boxes are generating constant heat rather than remaining at a constant temperature. Lastly, all propellant thermal properties are from Reference 11, aluminum honeycomb properties from Reference 12, and most other uncommon thermal properties from Reference 13.

$$
\bar{h}=\left(\frac{5}{4} * \frac{2}{360^{\frac{1}{5}}}\right) * \frac{1}{L^{\frac{1}{5}}} *\left(\frac{\operatorname{Pr}}{\frac{4}{5}+\operatorname{Pr}}\right)^{\frac{1}{5}} *\left(\frac{g \beta q}{\alpha v k}\right)^{\frac{1}{5}}
$$

Equation 1: Vertical Surface

$$
\bar{h}=0.611 *\left(\frac{L}{k}\right) *\left(\frac{g \beta q^{\prime \prime}}{\alpha v k}\right)^{\frac{1}{5}}
$$

Equation 2: Hot Surface Facing Up

$$
\bar{h}=0.351 *\left(\frac{L}{k}\right) *\left(\frac{g \beta q^{\prime \prime}}{\alpha v k}\right)^{\frac{1}{5}}
$$

\section{Equation 3: Hot Surface Facing Down}

After the application of these convection equations revealed heat transfer coefficients much lower than for a typical airplane flying in Earth's atmosphere, it was surmised that radiation heat transfer would play a more important role in the overall thermal environment of the AFV. The use of the method and data listed in Reference 14 for radiation parameters as a function of solar longitude, position, and optical depth led to the development of the following equations for the absorbed radiation on the top and bottom surfaces. In these equations, the radiation flux is broken into a direct component $\left(G_{d}\right)$, a diffuse component $\left(G_{b}\right)$, and a reflected (or albedo) component (Gal) and the calculations are made using the solar absorptivity $(\alpha)$ and the emissivity $(\epsilon)$.
For top surfaces:

$$
\begin{gathered}
\mathrm{G}_{\mathrm{al}}=0 \\
\mathrm{G}_{\text {top }}=\alpha \mathrm{G}_{\mathrm{d}}+\epsilon \mathrm{G}_{\mathrm{b}}
\end{gathered}
$$

For the bottom surfaces:

$$
\begin{gathered}
\mathrm{G}_{\mathrm{d}}=0 \\
\mathrm{G}_{\mathrm{bot}}=\alpha \mathrm{G}_{\mathrm{al}}+\epsilon \mathrm{G}_{\mathrm{b}}
\end{gathered}
$$

\section{MODEL DEVELOPMENT}

Taking the knowledge gained by the research into the atmosphere of Mars, including its effects on the convection and radiation heat transfer to and from the vehicle, a FEM model was developed using MSC.Patran and analyzed using MSC.Patran/Thermal (Ref. 15). It was created from the ProEngineer CAD model containing all the internal components of the fuselage (see Fig 2). In an effort to make the size of the model manageable and assuming a large thermal discontinuity at the first wing and tail folds, the model included only the fuselage and the inboard wing sections. The current model is shown in Figure 3.

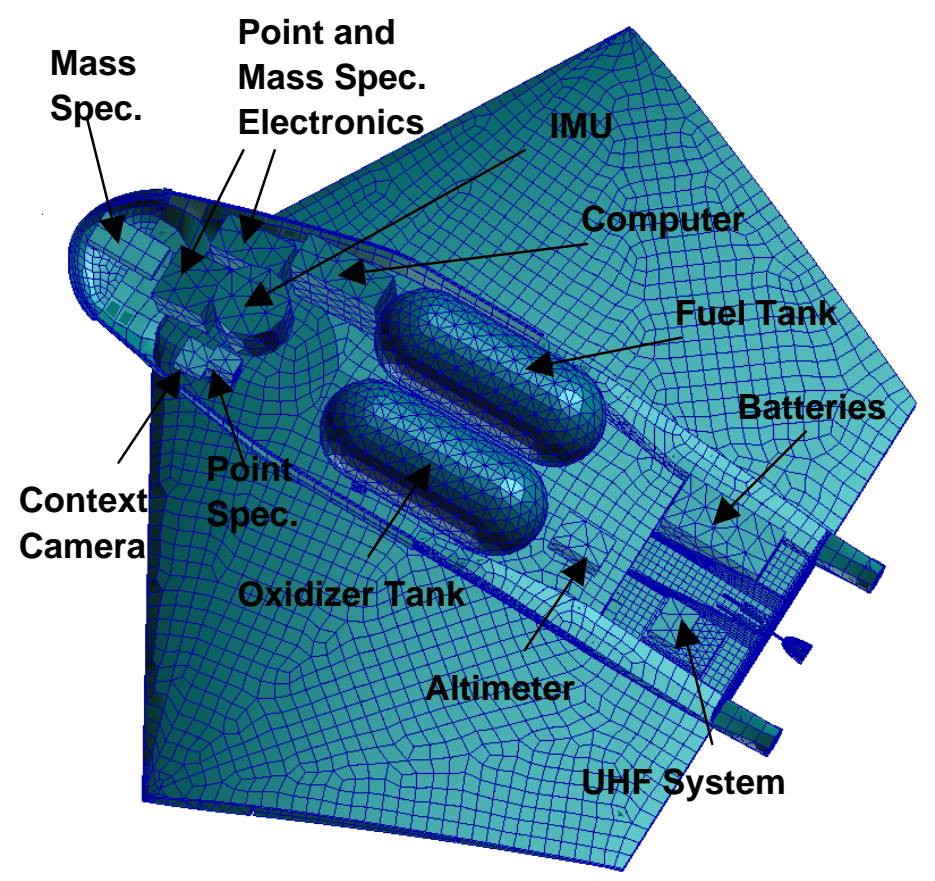

Figure 3 - Current FEM thermal model of fuselage

This model includes the heat generation by each component (see Table 1, Appendix 1) and a set of timedependent temperature boundary conditions for the rocket nozzle and throat section based on Reference 16. The convection and radiation boundary conditions discussed in the preceding section are included and can be adjusted to perform trade studies on extremes of the atmospheric parameters (such as flying on a cold day or 
with a 3-sigma low value of density from MarsGRAM) or to assess the impact of external factors (moving internal components, forcing the boundary layer turbulent, or applying thermal control). The inclusion of heaters in the model and their analysis will be discussed in a later section. Initial flight-phase analyses were performed using starting temperatures of $0^{\circ} \mathrm{C}$ for all items. Later analyses updated these values to reflect the results of the cruise, coast, and entry phases, discussed later in this paper.

\section{AFV THERMAL CONTROL DEVELOPMENT}

After development of the thermal FEM model, the development of the AFV thermal control system could proceed toward a solution. Due to the nature of ARES as a short-duration, one-flight mission, it was essential to design all subsystems for high reliability. However, they also had to be designed for low mass, since AFV pullout dynamics limit the total mass of the vehicle. Any mass saved in one subsystem can be applied to other areas to increase performance margins or add redundancy.

\section{UHF TRANSMITTER THERMAL CONTROL}

The nature of the UHF transmitter amplifier as the largest thermal concern made it the top priority in the AFV thermal control system. Directly related to the aforementioned themes of high reliability and low mass, active cooling systems, such as refrigerated cooling loops and other actively pumped systems, were immediately discarded as solutions. Efforts focused on passive systems that would provide higher reliability while maintaining low mass.

\section{Initial Concepts}

The development of the UHF transmitter thermal control system required pursuing ideas from both the spacecraft and aircraft thermal control areas. One spacecraft thermal control method that seemed ideal for moving heat from one area to another (since inevitably we would have areas of the vehicle which would need some type of heating) was the heat pipe (Ref. 17). Unfortunately, the reliability and effectiveness of heat pipes comes into question when dealing with a variable gravity field (such as a diving or banking aircraft), so this idea was discarded before detailed analyses were started. Another idea that was frequently suggested in thermal control design literature was packing the assembly in a phase change material (PCM). This idea was discarded early in the design phase when it presented mass and packaging concerns. A sample calculation using a common PCM for this type of application is presented in Appendix 2.
Heat-Spreading with Pyrolytic Graphite

Another idea for moving the heat away from the UHF transmitter was by the use of some type of heat spreading device. A material commonly used to move heat on spacecraft and in many other applications is pyrolytic graphite (Ref. 18, 19), a material that has one of the highest known thermal conductivities. Several permutations on the concept of a heat-spreading strip were developed and analyzed using the thermal FEM model. The first concept was a long strip running longitudinally along the bottom of the fuselage. This concept attempted to move the heat from the hot area around the UHF transmitter forward to the cooler science compartment. As can be seen in the thermal plot of this concept shown in Figure 4 (seen after only 60 minutes), the pyrolytic graphite did not have a high enough thermal conductivity to move the heat away quickly enough.
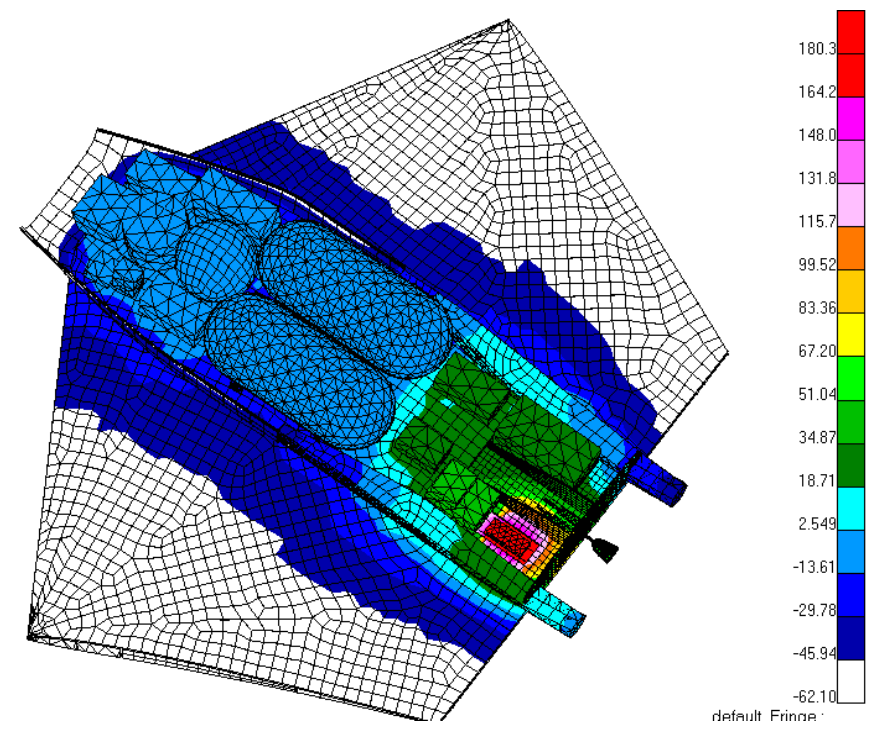

Figure 4 - Pyrolytic graphite insert results $\left({ }^{\circ} \mathrm{C}\right)$

Using this concept as a reference, other means of heat rejection in association with the heat spreading were considered, since conduction alone was not enough to cool the assembly. The main outlet of heat rejection was through the skin to the cold Martian atmosphere. For this concept, the UHF amplifier was moved to the inside surface of the upper skin of the fuselage. The aluminum honeycomb core in the vicinity was replaced with a pyrolytic graphite insert. In this way, the heat would be spread and then rejected through the skin to the atmosphere. Several sizes and configurations of pyrolytic graphite inserts were modeled. Ultimately, this concept proved to keep the UHF amplifier below its maximum operating temperature of $70^{\circ} \mathrm{C}$ as shown in Figure 5 (after 2 hours), but was approximately $4 \mathrm{~kg}$ in mass. This mass was very large when compared to the original estimates for the thermal control system of the 
AFV and it was desired that another, lighter option be found.

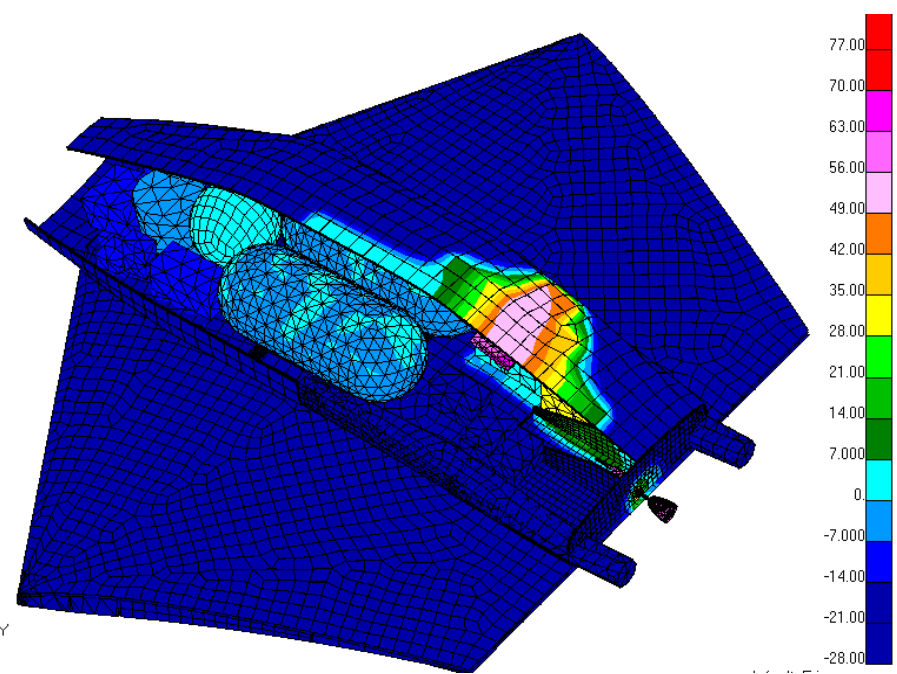

Figure 5 - Pyrolytic graphite roof insert results $\left({ }^{\circ} \mathrm{C}\right)$

\section{$\underline{\text { Heat Sink }}$}

Building on the concept of heat rejection through the skin to the external flow, another concept was evaluated that was built on a familiar thermal control device - a heat sink. A heat sink mounted to the bottom of the UHF transmitter amplifier that protruded through the fuselage into the external flow would provide much more effective area for convective heat transfer and would hopefully be much lighter than the pyrolytic graphite insert. This would contribute to drag on the vehicle, but according to the aerodynamicists working on the AFV outer mold line (OML), there would be a negligible effect on the overall drag provided the fins did not separate the flow. Thus, a finned heat sink appeared to be a viable concept.
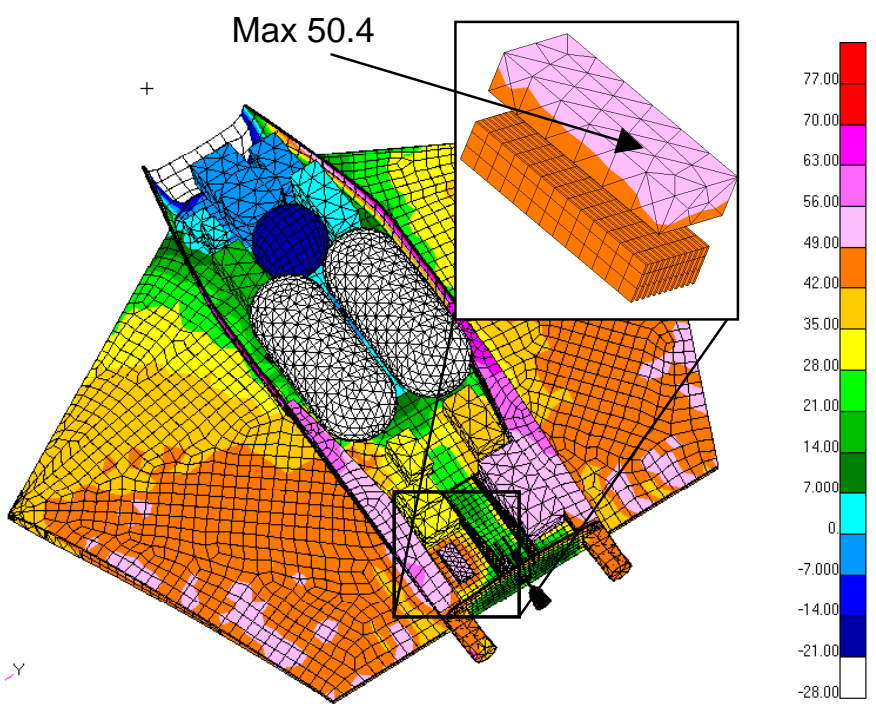

Figure 6 - Results with heat sink added; insert showing maximum temperature on UHF amplifier $\left({ }^{\circ} \mathrm{C}\right)$
Using the heat sink sizing program QFin 2.1 (Ref. 20), a baseline heat sink design was created. Table 2 in Appendix 1 shows the results of the trade study between different fin lengths, number of fins, and materials using QFin. QFin uses the equations for forced convection in air, but this was considered acceptable for this exercise since only a rough estimate of the heat sink size was required at this time. For ease of manufacture and low cost, aluminum was chosen as the heat sink material to be used in further thermal analyses, but this decision will be revisited later in the design process. Also, the design of the actual heat sink will require testing and is something for future work.

The results of the addition of the heat sink to the thermal FEM model are shown as a temperature contour plot in Figure 6; the heat sink is shown in the magnified detail of the figure. (NOTE: This plot is of a more detailed model completed later in the design and analysis process, explaining the differences in component temperatures from previous plots.) With its excellent performance and low mass of $0.228 \mathrm{~kg}$, the heat sink was deemed the most viable solution to the UHF transceiver assembly thermal problem.

\section{COATING ANALYSIS}

As mentioned above, radiation heat transfer to and from the AFV is a significant effect. Thus, it follows that the coating (or lack thereof) on the outside surfaces could have a major impact on the thermal environment of the internal components. To investigate this effect, a short trade study was performed using several different types of commonly used thermal control paints (values from Ref. 21, Appendix A), comparing the results to those with no coating applied (bare graphite composite). The effect is dramatic, especially when low alpha/epsilon paint is applied such as the Z93 white paint. The results show a dramatic decrease in component temperatures when using this type of paint (Figure 7). While adding a coating will also add additional mass to the thermal control system, its effect could be very beneficial in keeping key components operating in the colder end of their operating range. Also, it is possible that coating only certain parts of the fuselage would bring a similar benefit if applied in the vicinity of components that want to run cooler. These concepts are something that will be explored in later design and analysis efforts. 


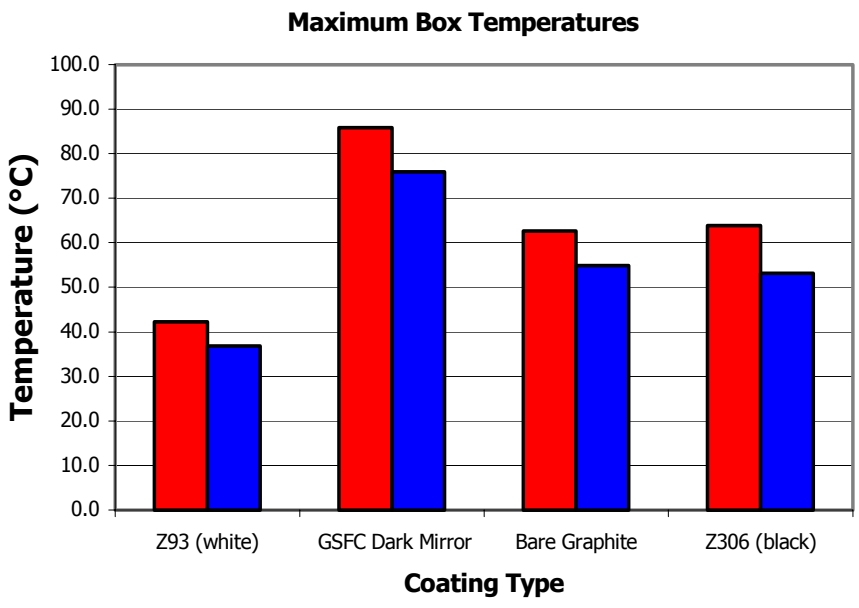

Figure 7 - Comparison of hot (red) and cold (blue) case maximum temperatures

\section{HEATER SIZING}

The sizing of heaters for use on the AFV was limited until a model that included the entire aeroshell and the folded wings and tail could be developed. These items were necessary since they could affect heater sizing and location, not only during operation in the Martian atmosphere but also during the cruise from Earth, coast from separation with the carrier spacecraft, and the Martian atmospheric entry. Therefore, models of the aeroshell, folded wings, and folded tail were developed and integrated with the original model of the fuselage and inboard wing structure. This complete FEM model (modified for clearer viewing) is shown in Figure 8.

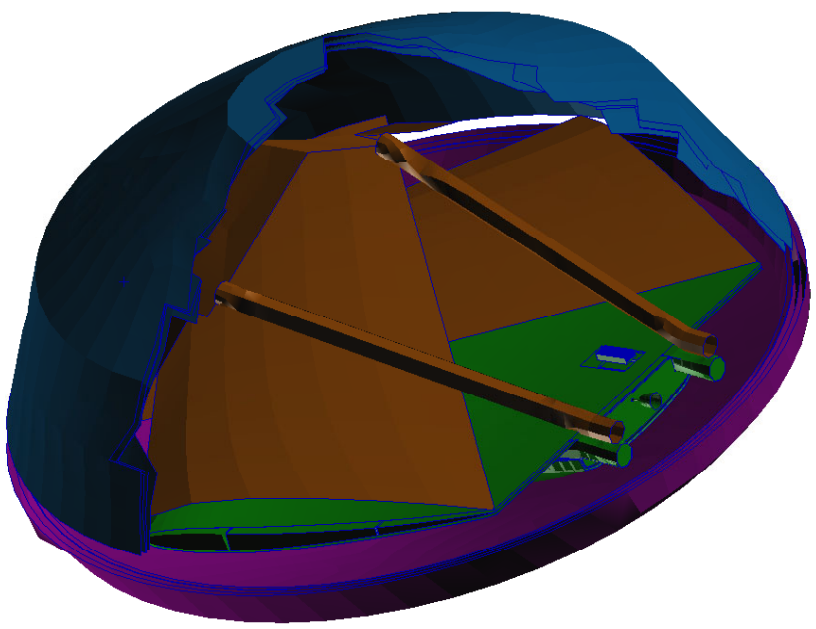

Figure 8 - Full FEM model of ARES while contained in the aeroshell (part of aftbody cut away for clarity)

\section{Analysis of Other Mission Phases}

Using this model, analysis was begun on the cruise, coast, and entry phases of the mission. The cruise phase was run as a steady-state model due to its long duration and constant configuration. During cruise the spacecraft shadows the aeroshell and the heat shield is pointed toward deep space. The results of the cruise phase were used as initial temperatures for the next phase of the analysis - the coast phase.

The coast phase was more difficult to analyze, as it needed the solar, planetshine, and albedo fluxes as boundary conditions. Using Thermal Desktop (Ref. 22), a model of the outer surfaces of the aeroshell was developed which produced these surface heat flux boundary conditions. The fluxes were based on a 9-hr coast trajectory generated for a Jan 182008 entry, but are considered to be representative of the actual entry date given it will occur within 6 months of that date. The model will be updated with a new trajectory when it is available.

These heat flux boundary conditions were applied to the FEM model using time-varying boundary conditions over the same surfaces that were defined in the Thermal Desktop model. The result of the absorbed heat flux can be seen in the plot seen in Appendix 3, along with pictures of the Thermal Desktop model pointing out which surfaces are listed in the plot. After application of these boundary conditions, the coast phase of the mission could be properly analyzed and its results passed to the entry phase analysis.

The entry analysis was developed last and was the least defined from a thermal point of view. At the time of this writing, the analysis and sizing of the heat shield thermal protection system (TPS) were not complete. In their absence, a time-varying temperature profile at the bond line between the TPS and the outer structural face sheet was taken from a representative case used for the Mars Pathfinder mission (Ref. 23). While the time-varying temperature will vary between Pathfinder and ARES, it is similar enough to get a rough estimate of the associated environment the AFV payload will experience during entry.

Using the combined effects of all mission phases in concert with the established analysis of the AFV flight, a temperature time history was developed for each component beginning at coast and proceeding until mission termination. This time history was then used to predict the heater power needed during the colder parts of the timeline. Including this prediction of heater power in the model in the form of surface mounted heaters and re-analyzing the timeline forms an iterative process for predicting required heater power. The thermostatically controlled heater option in MSC.Patran/Thermal was used to simulate surface heaters in the FEM model as 
an applied surface heat flux (Ref. 15). This analysis is still continuing, but some preliminary results for the heater power required fore each component are available and presented in Appendix 1, Table 3.

\section{PRELIMINARY RESULTS}

Results for the internal components of the AFV can be seen in the thermal plot shown in Figure 9. Figure 10 shows the temperature versus time plot for the science instruments and UHF system from coast until mission termination. The following parameters are used in arriving at the results presented:

- Flight Day: September 15, $2008\left(\mathrm{Ls}=129^{\circ}\right)$

- Flight Time: 1 PM LST

- External Atmospheric Temperature: $-\mathbf{7 0} 0^{\circ} \mathrm{C}$

- Internal Atmospheric Temperature: $-\mathbf{4 0} 0^{\circ} \mathrm{C}$

- Ground Radiation Sink Temperature: $-68^{\circ} \mathrm{C}$

- Optical Depth, $\tau: 0.5$

- Martian Surface Albedo: 0.15

- Fuselage Surface Boundary Layer: turbulent
These results represent the nominal flight profile and conditions expected for the September 2008 arrival. While many other off-nominal cases have been analyzed and designed for, in the interest of brevity they have been excluded here. The results presented in Figure 10 show that all components remain within their specified operating temperatures, with the exception of the point spectrometer, which violates its upper limit after approximately 15 minutes of flight. It is believed that planned changes in the placement and thermal isolation of the point spectrometer will resolve this issue; these changes will be included in the next iteration of the thermal model.
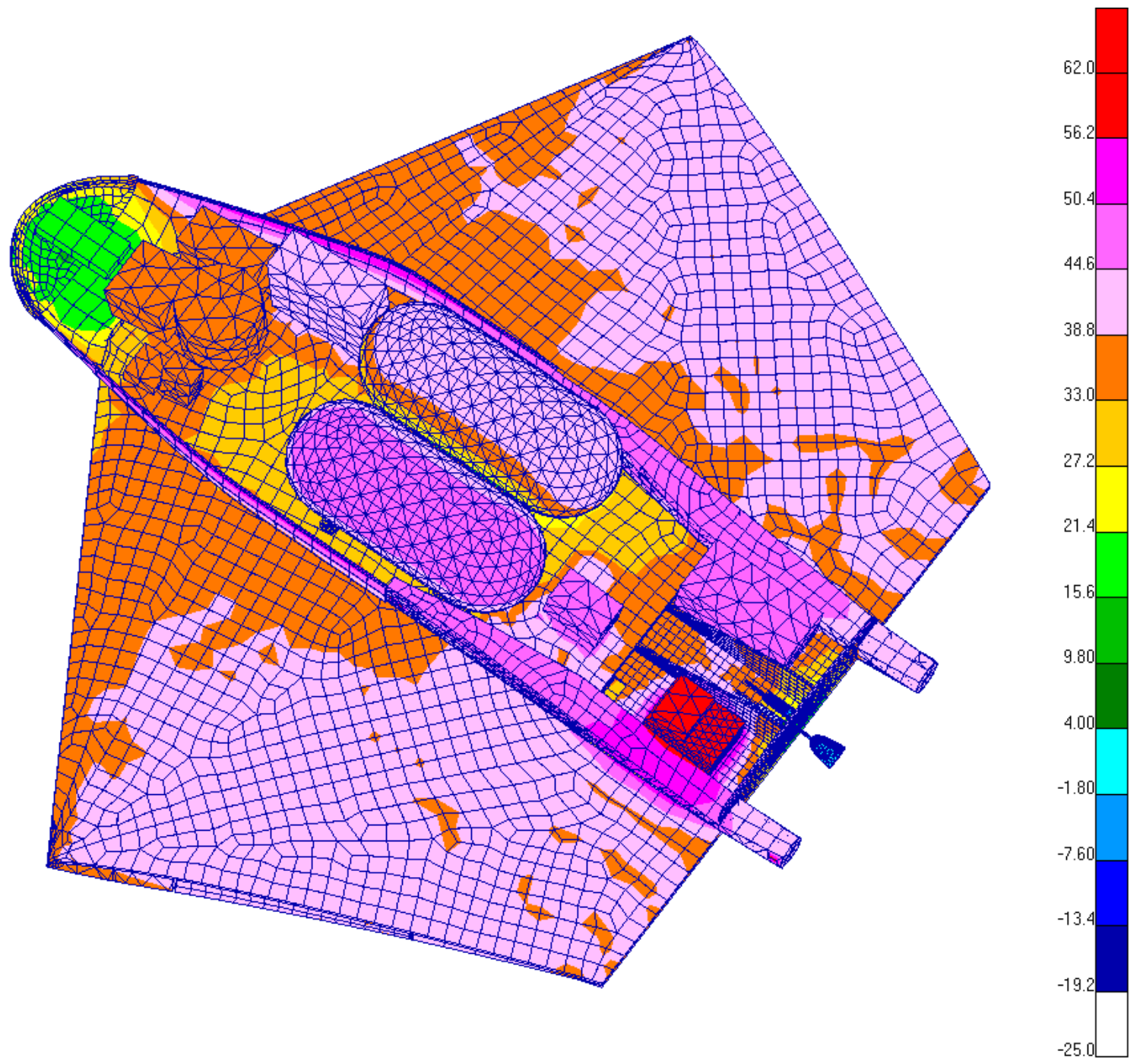

Figure 9 - Updated preliminary results for internal fuselage components after 83 minutes of flight $\left({ }^{\circ} \mathrm{C}\right)$ 


\section{Science and UHF Systems - Transient Temperatures}

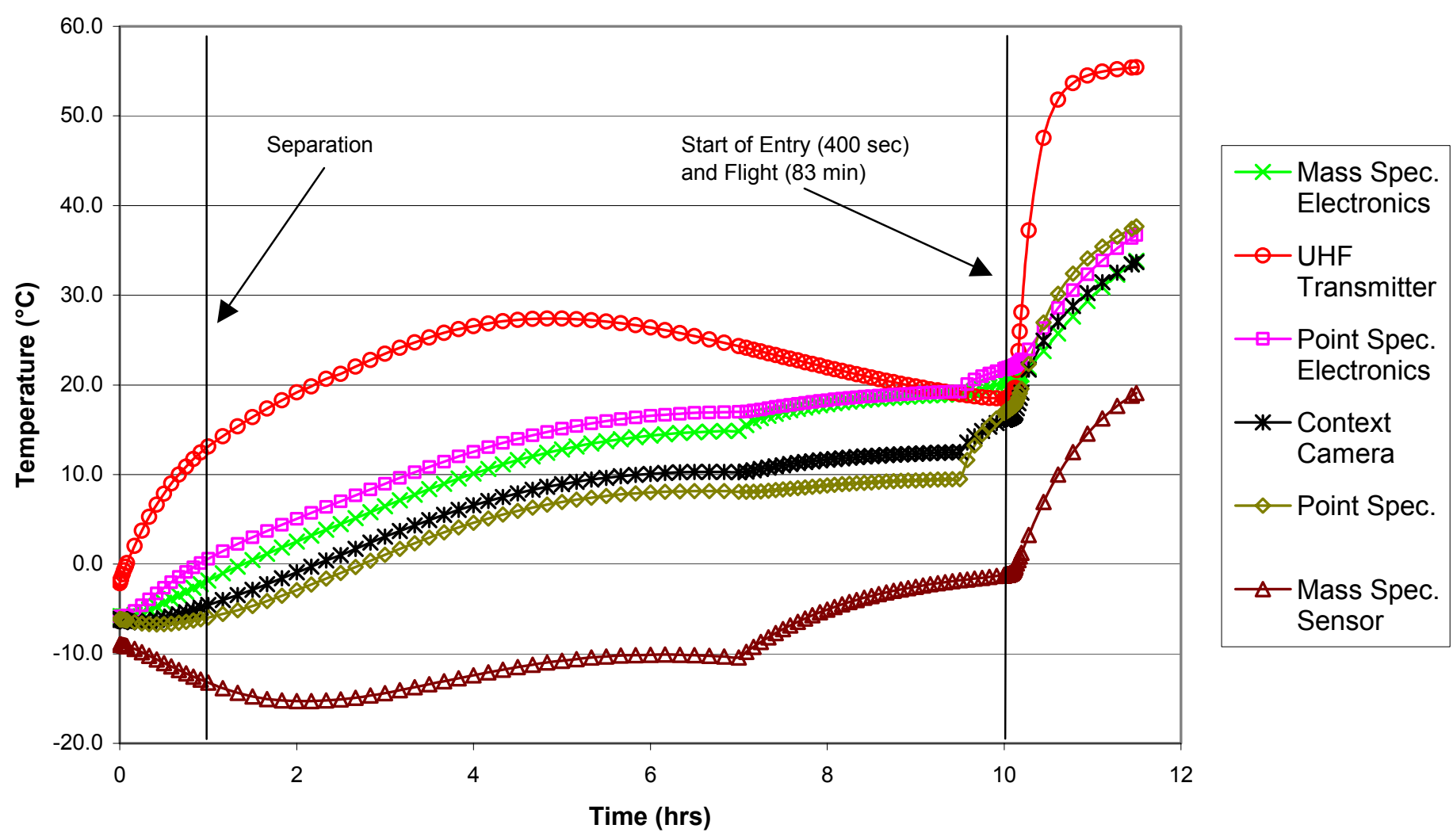

Figure 10 - Science and UHF system transient temperature results for entire mission profile $\left({ }^{\circ} \mathrm{C}\right)$

\section{CONCLUSION AND FUTURE WORK}

In summary, a FEM thermal model of the ARES AFV fuselage and inboard wing structure was developed and analyzed using data available on the flight parameters determined from the mission profile. This FEM model was used to predict thermal problem areas and to design and verify the use of passive, highly reliable, low mass thermal control solutions for the UHF transmitter amplifier. Further, this FEM model was incorporated into a larger FEM model of the entire packaged aeroshell including the folded tail section and outboard wings. This expanded FEM model was used to analyze the cruise from Earth, the coast from separation with the carrier spacecraft to Martian atmospheric interface, the entry, and finally the flight phase through its termination, resulting in vehicle and component temperature predictions throughout these phases. This analysis established a temperature time history for each component from cruise through flight, and showed that the thermostatically controlled surface heaters would be adequate to maintain the components at their required temperatures.
Despite the time and effort put forth in the preliminary design and analysis of the AFV thermal control system, much work remains. Each analysis done as a part of this preliminary effort must be reworked to include inevitable design changes in the AFV, as well as in the overall mission. The major areas of future work are:

- Revisit the coating analysis (paint scheme will be partly contingent upon input from the Education and Public Outreach section of ARES)

- Construct a new thermal model based on any design changes to the AFV, including a modified $\mathrm{OML}$, repackaging of internal fuselage components, and updated information on internal components

- Complete analysis of launch and transit to cruise orientation

- Analyze the effect of the rocket plume on the empennage and fuselage, and design appropriate thermal protection for those areas 
- Revisit the design of the heat sink, along with its placement and orientation

- Revisit selection of surface-mounted heaters and explore their exact placement based on external factors (proximity to structural components, detailed internal layout of each component, etc.)

\section{ACKNOWLEDGMENTS}

The authors would like to thank the entire ARES proposal team for their assistance and input to the items contained in this paper. Specific acknowledgement is given to the lead engineer for the proposal, Henry Wright, whose advice and input were required on a neardaily basis.

\section{REFERENCES}

1. Aerial Regional-scale Environmental Survey (ARES) proposal, NASA Langley Research Center, July 29, 2002.

2. Delta II Payload Planners Guide, The Boeing Company, Huntington Beach CA, October 2000.

3. ProEngineer 2001 Release Notes - Parametric Technology Corporation, Needham MA, April 2, 2001.

4. Levine, J. S. (Editor), 1985. _The Photochemistry of Atmospheres: Earth, The Other Planets and Comets, Academic Press, Inc., San Diego, CA, p. 346.

5. Y.S. Touloukian, P.E. Liley, S.C. Saxena, Thermophysical Properties of Matter, Volume 3: Thermal Conductivity of Nonmetallic Liquids and Gases, IFI/Plenum, New York, 1970.

6. C.L. Yaws, Physical Properties: A Guide to the Physical, Thermodynamic, and Transport Property Data of Industrially Important Chemical Compounds, McGraw-Hill Publishing Co., New York, 1977.

7. C.G. Justus, D.L. Johnson, "Mars Global Reference Atmospheric Model 2001 Version (MarsGRAM 2001): Users Guide", NASA TM210961, NASA Marshall Space Flight Center, April 2001.

8. A. Bejan, Convection Heat Transfer, $2^{\text {nd }}$ Edition, John Wiley and Sons Inc., New York, 1995.

9. E.M. Sparrow, J.L. Gregg, "Similar Solutions for Free Convection From a Nonisothermal Vertical Plate", Trans. ASME, Vol. 80, 1958, pp. 379386.

10. E.M. Sparrow, J.L. Gregg, "Laminar Free Convection From a Vertical Plate With Uniform
Surface Heat Flux", Trans. ASME, Vol. 78, 1956, pp. 435-440.

11. Chemical Propulsion Information Agency (CPIA) - Manual 4, John Hopkins Applied Physics Laboratory, Laurel, MD, 2001 ed.

12. HexWeb Honeycomb Attributes and Properties Manual, Hexcel Corporation, Pleasanton, CA, 1998.

13. TPSX Material Properties Database - Web Edition, Version 3, NASA Ames Research Center, http://tpsx.arc.nasa.gov, Retrieved January 11, 2002.

14. J. Appelbaum, D.J. Flood, "Solar Radiation on Mars - Update 1990", NASA TM-103623, NASA Lewis (Glenn) Research Center, October 1990.

15. MSC.Patran 2001 - Thermal User's Guide Volume 1, MSC.Software Corporation, 2001.

16. "Mars Flyer Rocket Risk Assessment, Final Report - Volume 1", TR-80291, Atlantic Research Corporation/Liquid Propulsion Division, December 1999.

17. P.D. Dunn, D.A. Reay, Heat Pipes $-4^{\text {th }}$ Edition, Pergamon Press, Oxford, England, 1994.

18. R.J. Holl, "Application of Pyrolytic Graphite to Space Radiators", $2^{\text {nd }}$ Annual AIAA Meeting, San Francisco, CA, AIAA 65-288, July 26-29, 1965.

19. H.J. Deacon, F.L. Mauritz, "Measurement of the Thermal Conductivities of Some Types of Beryllium and Carbon", $26^{\text {th }}$ AIAA

Thermophysics Conference, Honolulu, HI, AIAA 91-1394, June 24-26, 1991.

20. QFin 2.1 Users Manual, QFin Software, June 2000.

21. D.G. Gilmore, Satellite Thermal Control Handbook, The Aerospace Corporation Press, El Segundo, CA, 1994.

22. Thermal Desktop User's Manual, C\&R Technologies, Littleton, CO, Release 4.5, September 2002.

23. W.M. Congdon, "Ablation Model Validation and Analytical Sensitivity Study for the Mars Pathfinder Heat Shield", $30^{\text {th }}$ AIAA Thermophysics Conference, San Diego, CA, AIAA 95-2129, June 19-22, 1995.

24. V. Ashford, "X-38 Battery Heatsink Thermal Test Report", X38-BH2-TTR-02, Energy Science Laboratories Inc., San Diego, CA, January 2002.

25. G.S. Hickey, R. Manvi, T.R.Knowles, "Phase Change Materials for Mars Thermal Control", $26^{\text {th }}$ International Conference on Environmental Systems, Monterey, CA, ICES-961533, July 811, 1996. 
DEFINITIONS, ACRONYMS, ABBREVIATIONS

AFV: Atmospheric Flight Vehicle

ARES: Atmospheric Regional-scale Environmental Survey

CG: center of gravity

FEM: finite element (model)

$G_{\boldsymbol{d}}$ : direct (solar) component of global irradiation

$\boldsymbol{G}_{\boldsymbol{b}}$ : diffuse (infrared) component of global irradiation

$G_{a l}$ : reflected (or albedo) component

OML: outer mold line

$\alpha$ : (solar) absorptivity

$\epsilon$ : (infrared) emissivity 


\section{Appendix 1}

Table 1 - Operating temperatures and flight dissipations for each AFV component

\begin{tabular}{|c|c|c|c|}
\hline Component & $\begin{array}{c}\text { Minimum Op Temp } \\
\left({ }^{\circ} \mathbf{C}\right)\end{array}$ & $\begin{array}{c}\text { Maximum Op Temp } \\
\left({ }^{\circ} \mathbf{C}\right)\end{array}$ & $\begin{array}{c}\text { Flight Power Dissipation } \\
(\text { W) }\end{array}$ \\
\hline Oxidizer & 0 & 60 & 0 \\
\hline Fuel & -40 & 60 & 0 \\
\hline UHF Transceiver Assembly & -20 & 70 & 0 \\
\hline UHF Diplexer & -20 & 70 & 18.4 \\
\hline Radar Altimeter & -30 & 50 & 36 \\
\hline Battery Box & 0 & 55 & 39 \\
\hline Computer & -40 & 70 & 3.1 \\
\hline Mass Spectrometer & -20 & 30 & 6.9 \\
\hline Mass Spec Electronics & -20 & 55 & 4.6 \\
\hline Point Spectrometer & -10 & 25 & 12 \\
\hline Point Spec Electronics & -20 & 55 & 2.4 \\
\hline Context Camera & -10 & 25 & 12 \\
\hline Inertial Measurement Unit & -40 & 70 & \\
\hline
\end{tabular}

Table 2 - Results of heat sink trade study using QFin 2.1

\begin{tabular}{|c|c|c|c|c|c|c|c|}
\hline $\begin{array}{c}\text { Width } \\
(\mathbf{m m})\end{array}$ & $\begin{array}{c}\text { Depth } \\
(\mathbf{m m})\end{array}$ & $\begin{array}{c}\text { Number } \\
\text { of Fins }\end{array}$ & $\begin{array}{c}\text { Fin Length } \\
(\mathbf{m m})\end{array}$ & $\begin{array}{c}\text { Pressure Drop } \\
(\mathbf{P a})\end{array}$ & $\begin{array}{c}\text { Heat Sink Base } \\
\text { Temp }\left({ }^{\circ} \mathbf{C}\right)\end{array}$ & Material & Mass (kg) \\
\hline $\mathbf{5 0}$ & $\mathbf{1 3 0}$ & $\mathbf{1 1}$ & $\mathbf{2 0 . 2}$ & $\mathbf{3 5 8}$ & $\mathbf{6 8 . 1}$ & Aluminum & $\mathbf{0 . 2 2 8}$ \\
\hline 50 & 130 & 11 & 21.3 & 349 & 63.6 & Carbon Graphite & 0.196 \\
\hline 50 & 130 & 11 & 19.9 & 361 & 68.9 & Copper & 0.750 \\
\hline 100 & 130 & 16 & 12.0 & 234 & 68.6 & Carbon Graphite & 0.270 \\
\hline
\end{tabular}

Table 3 - Heater power requirements

\begin{tabular}{|c|c|}
\hline Component & Heater Power Required (W) \\
\hline Oxidizer & 20.0 \\
\hline Fuel & 15.0 \\
\hline UHF Transceiver Assembly & 3.0 \\
\hline UHF Diplexer & 2.0 \\
\hline Radar Altimeter & 20.0 \\
\hline Battery Box & 5.0 \\
\hline Computer & 3.0 \\
\hline Mass Spectrometer & 3.0 \\
\hline Mass Spec Electronics & 1.0 \\
\hline Point Spectrometer & 3.0 \\
\hline Point Spec Electronics & 1.0 \\
\hline Context Camera & 1.0 \\
\hline IMU & \\
\hline &
\end{tabular}




\section{Appendix 2}

Sample calculation of phase change material for UHF transmitter heat dissipation (Ref. 24, 25)

Sample PCM used for this calculation:

Latent Heat of Fusion:

UHF transmitter assembly dissipation:

Flight time:

Total Energy to be dissipated:

Rough estimate of PCM weight: n-docosane (a common space-rated wax-type PCM)

$180 \mathrm{~kJ} / \mathbf{k g}$ (includes embedded structure but not container)

approximately $100 \mathrm{~W}$

$83 \min =4980$ seconds

$100 \mathrm{~W} * 4980$ seconds $=498 \mathrm{~kJ}$

Energy to be dissipated / Latent Heat of Fusion of PCM $498 \mathrm{~kJ} / 180 \mathrm{~kg} / \mathrm{kg}=\mathbf{2 . 7 7} \mathbf{~ k g}$ 


\section{Appendix 3}

Data from Thermal Desktop for Jan 2008 arrival trajectory, post-separation from carrier spacecraft

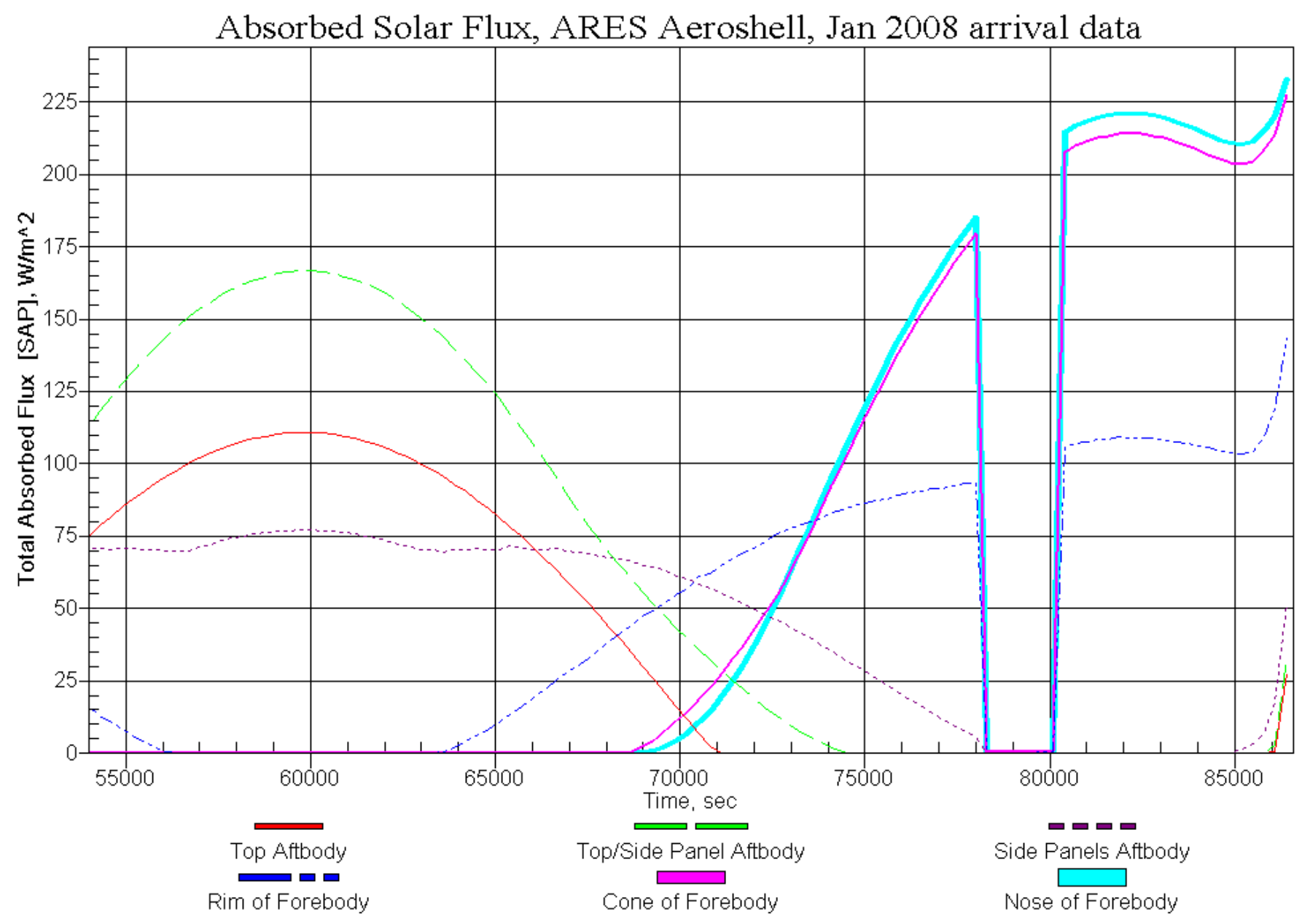

Thermal Desktop Aeroshell Model (Colors correspond to index above)
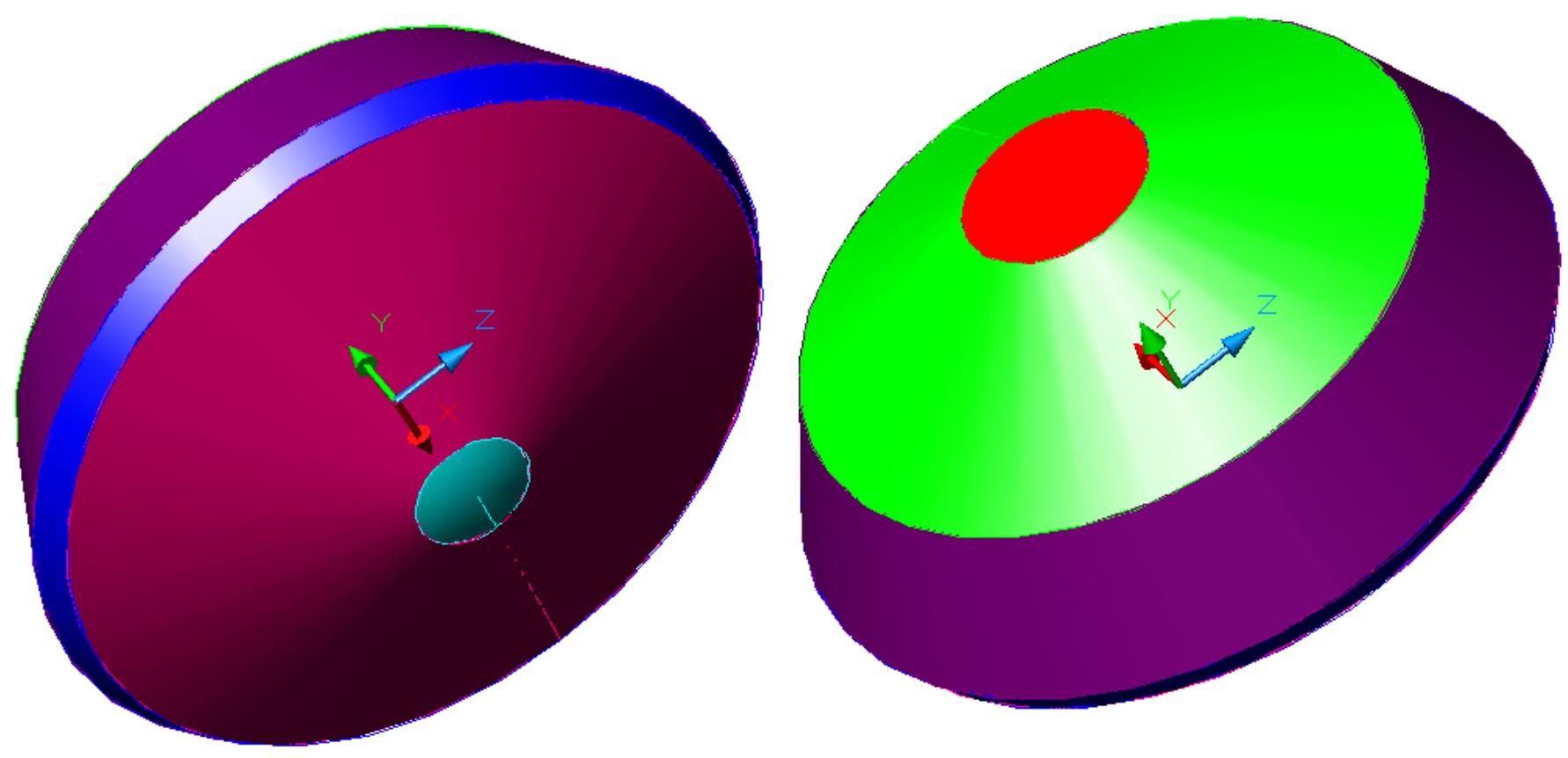